Bangladesh J. Bot. 49(3): 445-450, 2020 (September)

\title{
BIOCHEMICAL AND QUALITY PARAMETERS OF BTRI RELEASED TEA CLONES
}

\author{
M YASIN, R ARA, MSA MAMUN ${ }^{1}$ AND MM HoQUE* \\ Department of Food Engineering \& Tea Technology, Shahjalal University of \\ Science \& Technology, Sylhet, Bangladesh
}

Keywords: Tea, BT clones, Biochemical, Quality parameters, Antioxidants

\begin{abstract}
The quantity of antioxidant, flavanols, flavonoids, polyphenols, and catechins biochemical compounds varies among the clones and varieties. Biochemical parameters of green leaves and made tea were analyzed with standard methods using UV-visible spectrophotometer. Different biochemical and quality parameters varied markedly $(\mathrm{p}<0.05)$ among the test clones. Moisture per cent $(3.0$ and 2.73$)$, polyphenol (78.52 and $84.44 \mathrm{ppm}$ ), caffeine (68.28 and $70.3 \mathrm{ppm}$ ), antioxidant activity (96.4 and 97.39), theaflavin and thearubigin (ratio of TF and TR conc.; 9.99 and 9.99) contents were optimum in BT2 and BT4 clones.
\end{abstract}

\section{Introduction}

Tea has historically been promoted for having a variety of positive health benefits (Ulrike et al, 2011) and it is widely consumed because of these benefits, which are related to the biochemical components of tea. Consumption of tea (especially green) is potentially beneficial to health and longevity given by its antioxidant, flavanols, flavonoids, polyphenols, and catechins content (Shimizu et al. 2012). These components vary from clone to clone and variety to variety. They also depend on environmental and topological condition. Erol et al. (2010) investigated the content of polyphenols, antioxidant activity and alkaloids of seven grades of Turkish black tea. Arachchi et al. (2011) revealed that the fermentation rate could be used as a selection criterion to determine fermentation properties of tea and identify potential quality accessions during the early stages of the tea breeding program. Moraes-de-Souza et al. (2008) studied processed tea and herbal infusions for their phenol content, antioxidant activity and main flavonoids. Seasonal and clonal variations in catechins, flavour component 2-phenylethanol and prephenatedehydratase (PDT) enzyme were studied in tea clones representing both Assam and China varieties growing in Kangra region of India (Vaishali et al. 2010). Bangladesh Tea Research Institute (BTRI) has already released 18 clones. In the present study an experiment was carried out to investigate the variation in BTRI released clones in respect of biochemical and quality parameters. It will be constructive to detect the best clones of BTRI with better biochemical components.

\section{Materials and Methods}

The samples were collected from Bangladesh Tea Research Institute (BTRI), Srimangal, Moulvibazar. Sampling was made three times in a plucking year (Early April, mid-June and late September) for determining the clonal variations. Tea leaves then prepared in the laboratory using general method of tea preparation.

The moisture content was measured according to the official method 44-01 of AACC (2000). At first $1.0 \mathrm{~g}$ of sample was taken and placed in an oven set at $105^{\circ} \mathrm{C}$ for $3 \mathrm{hrs}$. The sample was allowed to cool. Then the weight of the cooled sample was measured. The sample was heated

*Author for correspondence: <hoquemm@gmail.com>. ${ }^{1}$ Entomology Division, Bangladesh Tea Research Institute, Srimangal, Moulvibazar, Bangladesh. 
again at $105^{\circ} \mathrm{C}$ for $30 \mathrm{~min}$ and cooled in a desiccator and weight was measured. This process of heating was repeated until the difference between two successive weighing is less than $1 \mathrm{mg}$. The lowest weight was recorded. The moisture content of the sample is calculated using the following formula:

$$
\text { Moisture }(\%)=\frac{(\text { Weight of dried sample }(\mathrm{g})}{\text { Weight of fresh sample }(\mathrm{g})} \times 100
$$

Dry matter content $(\%)(D M C)=100-$ moisture $(\%)$

Tea shoot comprising two leaves and an apical bud (about $1.0 \mathrm{~g}$ ) was ground well with $100 \%$ ethyl alcohol. The contents were filtered and made up to $50 \mathrm{ml}$ with ethyl alcohol. One $\mathrm{ml}$ of the alcoholic extract was diluted to $50 \mathrm{ml}$ with distilled water. Two $\mathrm{ml}$ of diluted extract was added with $4 \mathrm{ml}$ of $1: 1$ Folin-Ciocalteu's reagent and water mixture and $2 \mathrm{ml}$ of $35 \%$ sodium carbonate. The contents were further made up to $10 \mathrm{ml}$ with distilled water and the mixture was shaken thoroughly and allowed to stand still for $30 \mathrm{~min}$. Absorbance of the blue color developed was read at $700 \mathrm{~nm}$ against the reagent blank using UV-visible spectrophotometer. Quantum of polyphenols present in tea leaves was computed using the standard calibration curve derived from known concentrations (10 to $50 \mathrm{ppm}$ ) of gallic acid and the results were expressed as per cent gallic acid equivalents (Choudhury and Goswami 1983). To estimate caffeine, $50 \mathrm{ml}$ distilled water was heated at $40^{\circ} \mathrm{C}$ and then $100 \mathrm{mg}$ tea sample was stirred for $30 \mathrm{~min}$. Then it was filtered and cooled to room temperature. The $50 \mathrm{ml}$ of chloroform were poured into the tea infusion and stirred for 10 min. The water phase was separated from the organic phase (Chloroform) with a separating funnel. The organic solution was poured into quartz of UV cell and absorbance was taken in 260 $\mathrm{nm}$. Quantum of caffeine present in tea leaves was computed using the standard calibration curve derived from known concentrations ( 0 to $20 \mathrm{ppm}$ ) of caffeine and the results were expressed as per cent caffeine equivalents (Maidon et al. 2012).

The scavenging effects of tea samples for 1,1-diphenyl-2-picrylhydrazyl (DPPH) radical were measured according to the method by Chan et al. (2007). $2.0 \mathrm{ml}$ aliquot of test sample (in methanol) was added to $2.0 \mathrm{ml}$ of $0.16 \mathrm{mM}$ DPPH methanolic solution. The mixture was vortexed for $1 \mathrm{~min}$ and then left to stand at room temperature for $30 \mathrm{~min}$ in the dark and then absorbance was measured at $517 \mathrm{~nm}$ wave length in UV Spectrophotometer. The ability to scavenge the DPPH radical was calculated using the following equation:

Scavenging effect $(\%)=[1-($ A sample - A sample blank $) / A$ control $] \times 100$

where, 'A control' is the absorbance of the control (DPPH solution without sample); 'A sample' is the absorbance of the test sample (DPPH solution plus test sample) and 'A sample blank' is the absorbance of the sample only (sample without DPPH solution).

Two g of each tea sample were weighed and transferred in a $250 \mathrm{ml}$ conical flask. Boiled water $(100 \mathrm{ml})$ was added to the sample and the contents were infused over the boiling water bath for 10 min with intermittent shaking. It was then filtered through cotton wool and the analysis was carried out as stated in Fig.1. Contents of TF and TR were calculated from the absorbance values where, $\mathrm{TF}(\%)=(4.313 \times \mathrm{B} \times 2 \times 100) /($ Sample weight $\times \mathrm{DMC})$ and TR $(\%)=(13.643 \times(\mathrm{A}+\mathrm{C}-$ B) $\times 2 \times 100) /($ Sample weight $\times$ DMC $)$. Multiplication factors of TF and TR were derived from molar extinction coefficients of pure compounds and dilution factor (Roberts and Smith 1963).

The experimental data were analyzed using analysis of variance (ANOVA) adjudged by DMRT $(\mathrm{p}<0.05)$ to determine a significant difference among samples. The data were analyzed by using SPSS-20 statistical software (SPSS Inc., Chicago, IL, USA). 


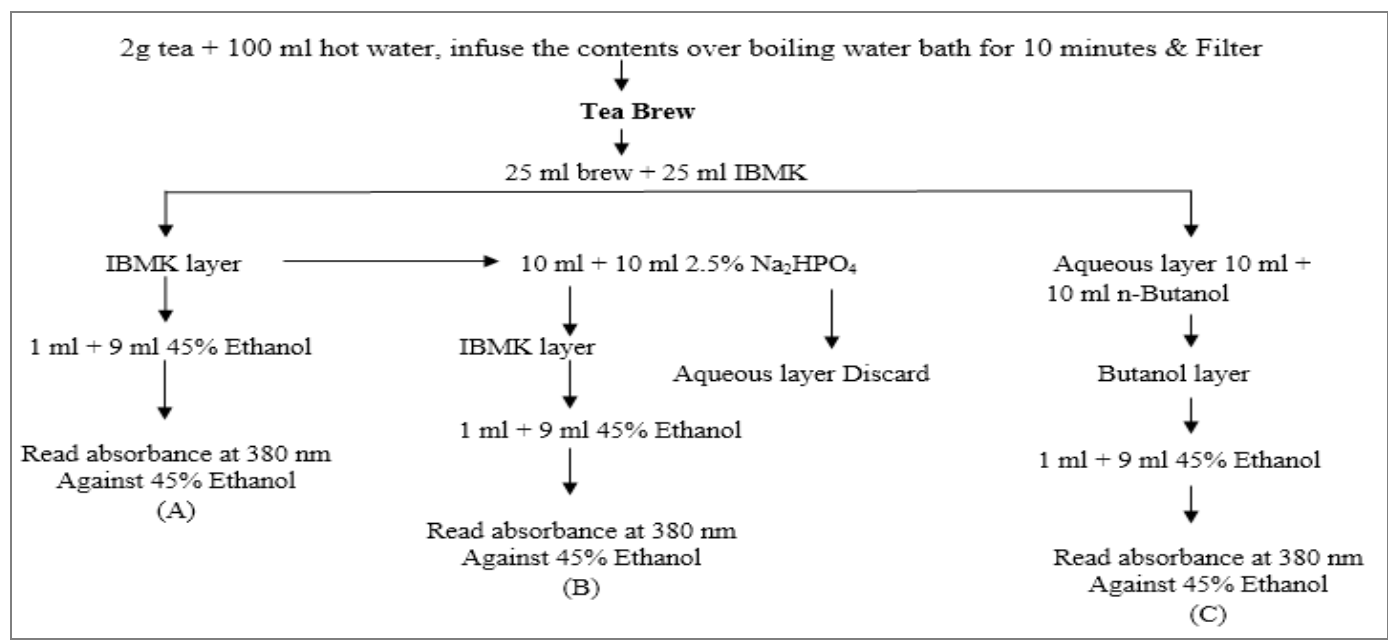

Fig. 1. Estimation of TF and TR in black tea by UV spectrophotometer.

\section{Results and Discussion}

The moisture content (MC) of tea not only determines the shelf life of tea, but also affects the physical and chemical reactions in tea processing, so measurement of $\mathrm{MC}$ is an important task for producing high-quality tea (Okamura 2000). Moisture content mainly expresses the amount of free water present in the product. In the processed tea, the moisture content may be around 3\%.

\section{Moisture content}

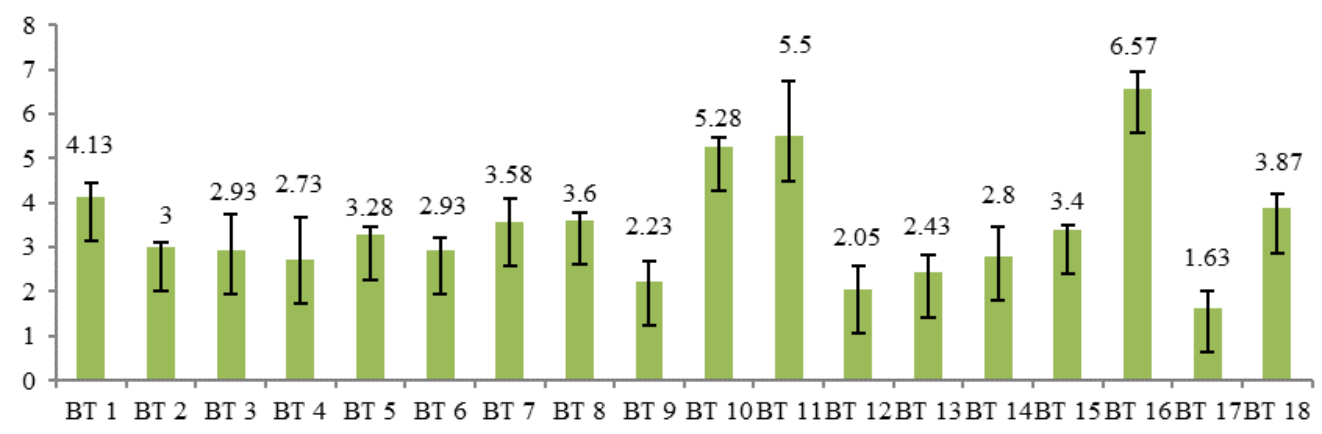

Fig. 2. Percentage of moisture content in BTRI released tea clones.

From the Fig. 2, it is apparent that the tea sample shows the moisture content level from 1.63 to $6.57 \%$. The moisture content should be near of $3.0 \%$. Apart from some clones like BT10, BT11, BT16 all other show the higher amount of moisture content percentage. Clones of BT1, BT2, BT5, BT6, BT8, BT10, BT15 show significant differences among the time of plucking.

Caffeine, which is found in tea and coffee, imparts bitterness and acts as a flavor constituent (Leo 1992). The caffeine content of the clones is not very dispersed. The rage was $54.61-71.53$ ppm. Here BT5, BT9, BT10, BT16, BT17 and BT18 were found to contain caffeine level below $60 \mathrm{ppm}$, while BT2, BT4 and BT6 contain caffeine level is above $65 \mathrm{ppm}$. It is also noted that BT6 contain highest amount of caffeine i.e. $71.53 \mathrm{ppm}$. Earlier studies revealed that caffeine 
content is associated to origin, genetic and environmental variability, harvest time and processing manner of plant material (Athayde et al. 2000) and can range from 24 to $40 \%$.

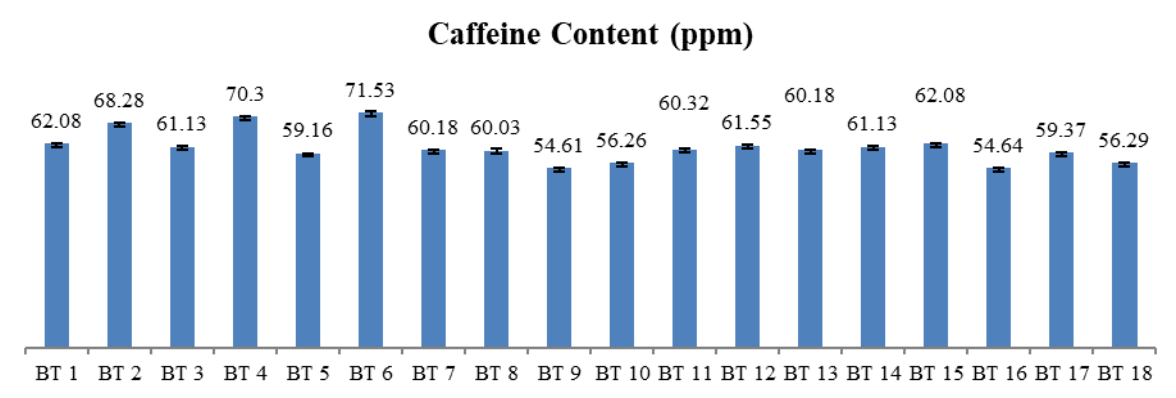

Fig. 3. Caffeine content in BTRI released tea clones.

Caffeine from tea is absorbed by the small intestine within $45 \mathrm{~min}$ of ingestion and then distributed through all tissues of the body. Adequate consumption of caffeine has various health effects. In Malawi, Cloughley (1982) has shown that the caffeine content of tea is influenced by seasonal, genetic, agronomic and cultural factors.

Polyphenols are the most significant group of tea components and have a wide range of pharmaceutical properties including antioxidative, anticarcinogenic and antiarteriosclerotic (Atoui et al. 2005). Depending on how the tea is harvested, handled, processed, and brewed, the polyphenol level in the tea can vary. The total polyphenol content in different tea clones was determined by Folin-Ciocalteu method (Jayasekera et al. 2011).

Polyphenol Content (ppm)

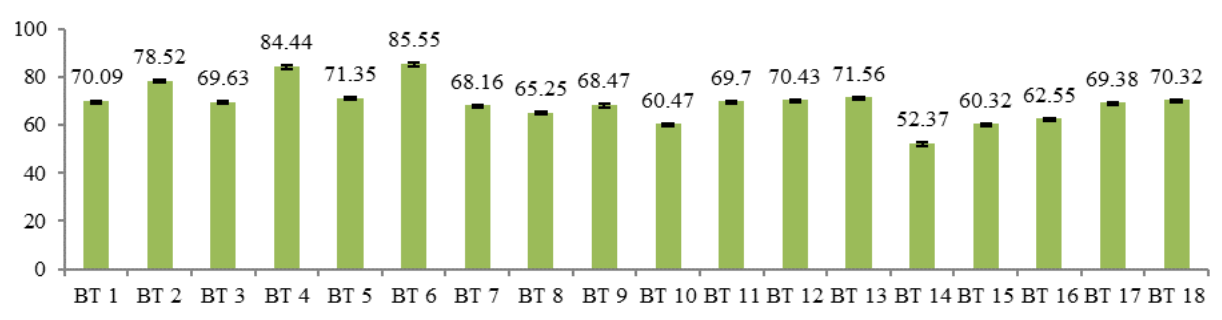

Fig. 4. Polyphenol content in BTRI released tea clones.

Polyphenol content in sample was found to vary ranging from $52.37-85.55 \mathrm{ppm}$. The mean of these samples was near around $65 \mathrm{ppm}$. The highest value was observed in BT 6, BT4 and BT2. While others also show a good satisfactory result. In addition, the lowest value was observed in BT 14, which is $52.37 \mathrm{ppm}$.

The pharmacological effects of tea are reviewed, including antioxidative activity (Satoshi and Hara 1990), antimutagenic (Yen and Chen 1994), and anticancer effects (Isao 1990). Concerning the antioxidative and anticarcinogenic effects of tea, Ruch et al. (1989) reported that green tea antioxidant (GTA) had antioxidative activity toward hydrogen peroxide and superoxide and that GTA prevented oxygen radical and hydrogen peroxide induced cytotoxicity and inhibition of intercellular communication in cell culture.

Antioxidants are molecules which inhibit the oxidation of organic molecules. They are very important not only for food preservation but also for the defense of living systems against 
oxidative stress. They are believed to play a role in preventing the development of such chronic disease as cancer, heart diseases, stroke, Alzheimre's diseases, and so on. The scavenging effect of the antioxidant present in the tea sample was mainly determined.

\section{Antioxidant Activity (\%)}

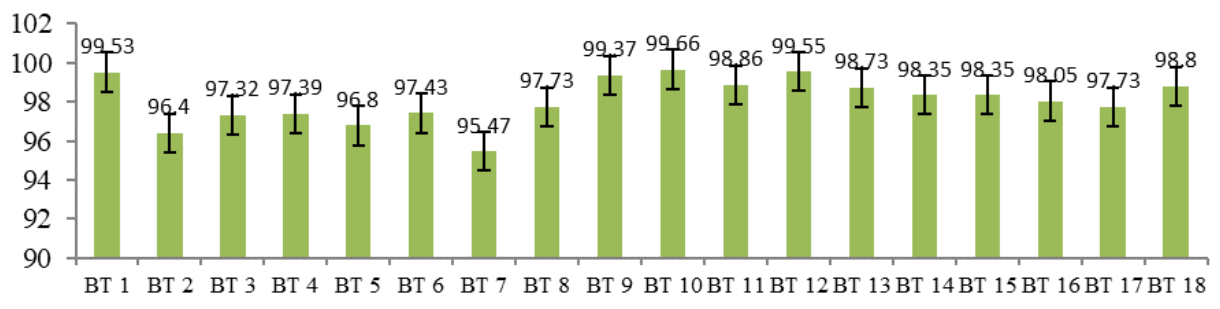

Fig. 5. Antioxidant activity in BTRI released tea clones.

Theaflavins possess a broad spectrum of biological functions, such as the anti-oxidative, antibacteria, anti-tumor, anti-viral, anti-inflammatory and cardiovascular protection activities (Lambert and Yang 2003). Thearubigins are red in colour and are responsible for much of the staining effect of tea. The colour of a black tea is affected by many other factors as well. The taste of tea liquor depends on the ratio of TF, TR concentrations. This ratio dominates the two important taste attributes like briskness and strength. However, these chemicals also determine the brightness and colour of tea liquor (Roberts 1962). Thus, there exist a correlation between colour of tea liquor and its taste.

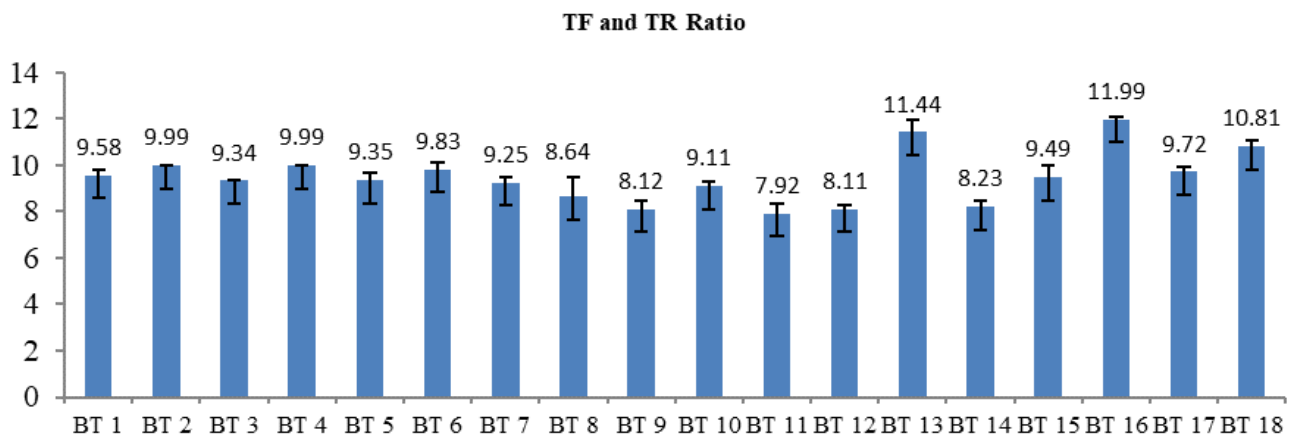

Fig. 6. TF and TR ratio in BTRI released tea clones.

Theaflavin and thearubigin formed as the result of enzymatic oxidation of polyphenols during the fermentation process of tea manufacture, which determine the colour of tea liquor. It is said that the ratio should be 10 for good quality tea. Less or more than 10 is not good for the quality of the tea. From the Fig. 6 it is apparent that BT 2 and BT 4 show the result near about 10, which is good for the clones. Therefore, the quality of BT 2 and BT 4 is superior to other clones.

\section{References}

AACC (American Association of Cereal Chemists) 2000. Approved methods of the American Association of Cereal Chemists 10th ed. St. Paul, MN, Method 44-01.

Arachchi KJD, Gunasekare MTK, Ranatunga MAB, Jayasinghe L and Karunagoda RP 2011. Analysis of selected biochemical constituents in black tea (Camellia sinensis) for predicting the quality of tea germplasm in Sri Lanka, Trop. Agril. Res. 23(1): 30-41. 
Athayde ML, Coelho GC and Schenkel EP 2000. Caffeine and theobromine in epicuticular wax of Ilex paraguariensis A. St. Hil. Phytochem. 55: 853-857.

Atoui AK, Mansouri A, Boskou G and Kefalas P 2005. Tea and herbal infusions: Their antioxidant activity and phenolic profile. Food Chem. 89: 27-36.

Chan EWC, Lim YY and Chew YL 2007. Antioxidant activity of Camellia sinensis leaves and tea from a lowland plantation in Malaysia. Food Chem. 102(4): 1214-1222.

Choudhury MND and Gowsamy MR 1983. A rapid method for determination of total phenolic matter in tea (Camellia sinensis L.). Two and a bud. 30: 59-61.

Cloughley JB 1982. Factors influencing the caffeine content of black tea. Part I. The effect of field variables. Food Chem. 9: 269-76.

Erol NT, Ferda SF and Velioglu YS 2010. Polyphenols, alkaloids and antioxidant activity of different grades Turkish black tea. The Assoc. Food Tech. 35(3): 161-168.

Isao T. 1990. Preventive effects of tea on cancer. Fragrance J. 11: 54-61.

Jayasekera S, Molan AL, Garg M and Moughan PJ 2011. Variation in antioxidant potential and total polyphenol content of fresh and fully-fermented Sri Lankan tea. Food Chem. 125: 536-541. doi: 10.1016/j.foodchem.2010.09.045.

Lambert JD and Yang CS. 2003. Mechanisms of cancer prevention by tea constituents, J. Nutr. 133: $3262-$ 3267.

Leo ML. 1992. Food analysis by HPLC. Marcel Decker Inc., pp. 656- 659.

Maidon ABMA, Mansoer AO and Sulistyarti H 2012. Study of various solvents for caffeine determination using UV spectrophotometer. J. Appl. Sci. Res. 8(5): 2439-2442.

Moraes-de-Souza RA, Oldoni TLC, Regitano-d’Arce MAB and Alencar SM 2008. Antioxidant activity and phenolic composition of herbal infusions consumed in Brazil, Comida ciência e Tecnologia, 6(1): 41-47.

Okamura S. 2000. Microwave technology for moisture measurement. Subsurf. Sens. Technol. Appl. 1: 205-227.

Roberts EA and Smith RF. 1963. The phenolic substance of manufactured tea IX. The spectrophotometric evaluation of tea liquors. J. Sci. Food Agric. 14: 689-700.

Roberts EAH. 1962. The chemistry of flavonoid compounds, Pergamon, New York. pp. 468-510.

Ruch RJ, Cheng SJ and Klauning JE. 1989. Prevention of cytotoxicity and inhibition of intercellular communication by antioxidant catechins isolated from Chinese green tea. Carcinogenesis 10: 1003-1008.

Satoshi S and Hara Y. 1990. Antioxidative activity of tea catechins. Fragrance J. 11: 24-30.

Shimizu M, Kubota M, Tanaka T and Moriwaki H 2012. Nutraceutical approach for preventing obesityrelated colorectal and liver carcinogenesis. Int. J. Mole. Sci. 13(1): 579-95.

Ulrike H, Moore CE, Silke DS, Tronnier H and Stahl W 2011. Green tea polyphenols provide photoprotection, increase microcirculation, and modulate skin properties of women. J. Nutri. 141(6): 1202-1208.

Vaishali S, Robin J and Ashu G 2010. Seasonal clonal variations and effects of stresses on quality chemicals and prephenatedehydratase enzyme activity in tea (Camellia sinensis). European Food Res. Tech. 232(2): 307-317.

Yen GC and Chen HY 1994. Comparison of antimutagenic effect of various tea extracts (green, oolong, pouchong and black tea). J. Food Prot. 57: 54-58.

(Manuscript received on 23 July, 2019; revised on 11 November, 2019) 